\title{
Correction to: Cancer Risk, Risk Reduction, and Screening and Treatment Access among U.S. South Asians
}

Francesca Gany, Anuradha Hashemi, Jennifer Leng, and Sayyeda Ayesha Ahmed

\section{Correction to:}

Chapter 8 in: M. J. Perera, E. C. Chang (eds.), Biopsychosocial Approaches to Understanding Health in South Asian Americans, Cross-Cultural Research in Health, Illness and Well-Being, https://doi.org/10.1007/978-3-319-91120-5_8

Owing to an oversight, one of the authors name and affiliation had been missed in the previous version. However, this has been corrected and the author "Sayyeda Ayesha Ahmed" has been added. 